\title{
A spoonful of sugar helps the medicine go down? A review of strategies for making pills easier to swallow
}

This article was published in the following Dove Press journal:

Patient Preference and Adherence

\author{
Aida Sefidani Forough' \\ Esther TL Lau' \\ Kathryn J Steadman ${ }^{1,2}$ \\ Julie AY Cichero ${ }^{1,2}$ \\ Greg J Kyle' \\ Jose Manuel Serrano \\ Santos' \\ Lisa M Nissen'
}

'School of Clinical Sciences, Faculty of Health, Queensland University of Technology, Brisbane, QLD, Australia; ${ }^{2}$ School of Pharmacy, University of

Queensland, Brisbane, QLD, Australia

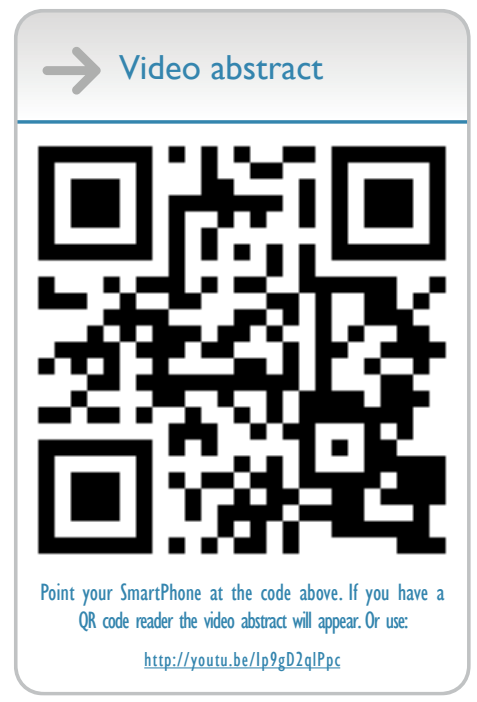

Correspondence: Aida Sefidani Forough School of Clinical Sciences, Faculty of Health, Queensland University of Technology, 2 George Street, Brisbane, QLD 4000, Australia

$\mathrm{Tel}+6|73| 38 \mid 490$

Email a.sefidaniforough@qut.edu.au

\begin{abstract}
Solid oral dosage forms such as tablets and capsules are generally the preferred method of drug delivery due to their convenience, cost, and acceptability. However, for many people, it can be a challenge to swallow solid oral medications, even those with healthy swallowing function. This review describes current strategies available to facilitate medication administration to otherwise healthy people with pill-swallowing difficulties. In general, restoring and maintaining the ability to swallow pills whole should ideally be the first choice in managing people with pill-swallowing difficulties. A number of strategies can potentially make it easier to swallow pills whole. These include postural adjustments, using pill-swallowing aids, and teaching pill-swallowing techniques. Where these are not successful or appropriate, then other approaches have to be considered using alternative formulations/routes of administration or deprescribing. If there is no other option, and it is not directly contraindicated for each specific medication dosage form, pills may be modified and mixed in foods and drinks to aid swallowing. In conclusion, people with pill-swallowing difficulties can benefit from a number of strategies designed to facilitate swallowing medications. However, these strategies should be further evaluated with regard to the evidence relating to both their efficacy and safety.
\end{abstract}

Keywords: swallowing difficulties, pill swallowing, medication administration, oral dosage forms, tablets, capsules

\section{Introduction}

The oral route is generally the preferred method of drug administration as it is often more convenient, cost-effective, and acceptable for patients. ${ }^{1}$ However, some people may find it difficult to swallow oral medications, especially solid dosage forms, eg, tablets and capsules, which is often defined as pill-swallowing difficulties. ${ }^{2}$ In this paper, pill-swallowing difficulties refer to otherwise healthy people who only experience difficulty swallowing solid dosage forms. These are distinctly different from medication swallowing difficulties that occur as a complication of dysphagia, ie, the physiologic impairment in swallowing function. ${ }^{3}$ Therefore, the strategies that are reviewed here are for healthy people with pill-swallowing difficulties and not for people with dysphagia-related medication swallowing difficulties as they require special considerations.

Pill-swallowing difficulties affect somewhere between 10 to $40 \%$ of the adult population. ${ }^{2,45}$ In some people, pill-swallowing difficulties may have emotional and psychological roots. Unpleasant or traumatic experiences associated with swallowing pills in the past such as gagging or choking can lead to an aversion to swallowing oral medications. ${ }^{6}$ Psychological swallowing difficulties with pills may also stem 
from people's different perceptions toward pills than foods especially when they try to ingest a solid substance without chewing. In severe cases, the aversion to swallow medications manifests itself as "pill phagophobia" or the fear of swallowing pills. $^{7}$ Physical characteristics of solid dosage forms such as shape, size, texture, and taste may also trigger medication swallowing difficulties in some people. ${ }^{1,8}$ For instance, pills that are large and have rough surface textures or an unpalatable taste are associated with reduction in ability to swallow the dosage forms. ${ }^{1,8}$

Pill-swallowing difficulties may eventually result in patients refraining from taking their medications. Up to $70 \%$ of community patients with medication swallowing difficulties and $20 \%$ of aged care residents reportedly skip medications because of their inability to swallow their medicines. ${ }^{8-10}$ Non-adherence to prescribed medicines can lead to poor disease management and a consequent increase in morbidity and mortality. ${ }^{11}$ Administering medications to people with swallowing difficulties is also a challenging task for health care professionals who have to overcome various uncertainties and challenges when managing drug therapy of these patients. ${ }^{12}$ In order to overcome the non-adherence and to make the medications easier to swallow, patients, caregivers and/or health care professionals may resort to unauthorized methods of administration such as crushing/splitting tablets or opening capsules. ${ }^{2,13,14}$ In fact, many people modify their oral medications in order to swallow them; $10-59 \%$ of community pharmacy customers self-reported modifying their medications before taking them., ${ }^{2,6,8}$ However, these practices can be associated with increased risk of medication misadventures, adverse drug reactions, and in some cases have had fatal consequences. ${ }^{15}$ It is concerning that many patients are unaware of the potential hazards of inappropriately crushing or splitting their tablets, or opening capsules, and rarely obtain advice from relevantly trained health care professionals before considering this approach. ${ }^{2}$

Since most medications are available in solid oral dose forms the ability to swallow them safely and effectively is particularly important. The relatively high prevalence of pill-swallowing difficulties in the community and the widespread use of unauthorized and potentially risky methods of medication modification mean both patients and health care professionals need to be armed with safe and effective strategies of medication administration. This review therefore describes current strategies for facilitating medication administration to people with pill-swallowing difficulties. It covers the body of literature around strategies for people with normal swallowing physiology who only have difficulty with swallowing solid dosage forms.

\section{Materials and methods}

The PubMed, CINAHL, Embase, and Google Scholar databases were searched using different combinations of keywords including medication administration, oral dosage form, swallowing difficulties, intervention, or other corresponding search terms based on each database's defined thesaurus. A complementary reference list search and citation tracking was also carried out to find potential articles that might have been missed in the initial database search. All articles were imported into the bibliography management software (EndNote ${ }^{\circledR}$ Version 7.0) and then classified based on the topic. The articles were included with no publication date restriction as the review aimed to cover all possible strategies used for medication administration in swallowing difficulties. Papers were included if they were relevant for swallowing difficulties and medications, and no restrictions were imposed on the study type or design.

\section{Strategies to facilitate pill swallowing}

Interventions for people with pill-swallowing difficulties can be studied based on the underlying causes of the swallowing problem. Our review only discusses the strategies for healthy population with pill-swallowing difficulties. Figure 1 illustrates the overall framework of this review and potential directions to the pill-swallowing research.

Restoring and maintaining the ability to swallow pills whole should ideally be the first choice in managing people with pill-swallowing difficulties. A number of strategies can potentially make it easier to swallow pills whole. These include postural adjustments, using pill-swallowing aids, and teaching pill-swallowing techniques. Where these are not successful or appropriate, then other approaches have to be considered using alternative formulations/routes of administration or de-prescribing. If there is no other option, and it is not directly contraindicated for each specific medication dosage form, then pills may be modified and mixed in foods and drinks to aid swallowing. However, where medications are modified from their original form, this is considered off-label use as it will not fall under a product's original license.

\section{Postural adjustments}

Postural adjustments focus on instructing patients to adjust their body and/or head and neck position to support swallowing function and make the swallowing process easier. More specifically, postural adjustments are designed to regulate the direction and flow of the ingested material and protect the airway from aspiration of swallowed materials. ${ }^{16}$ A safe position for swallowing directs the oral bolus to easily 


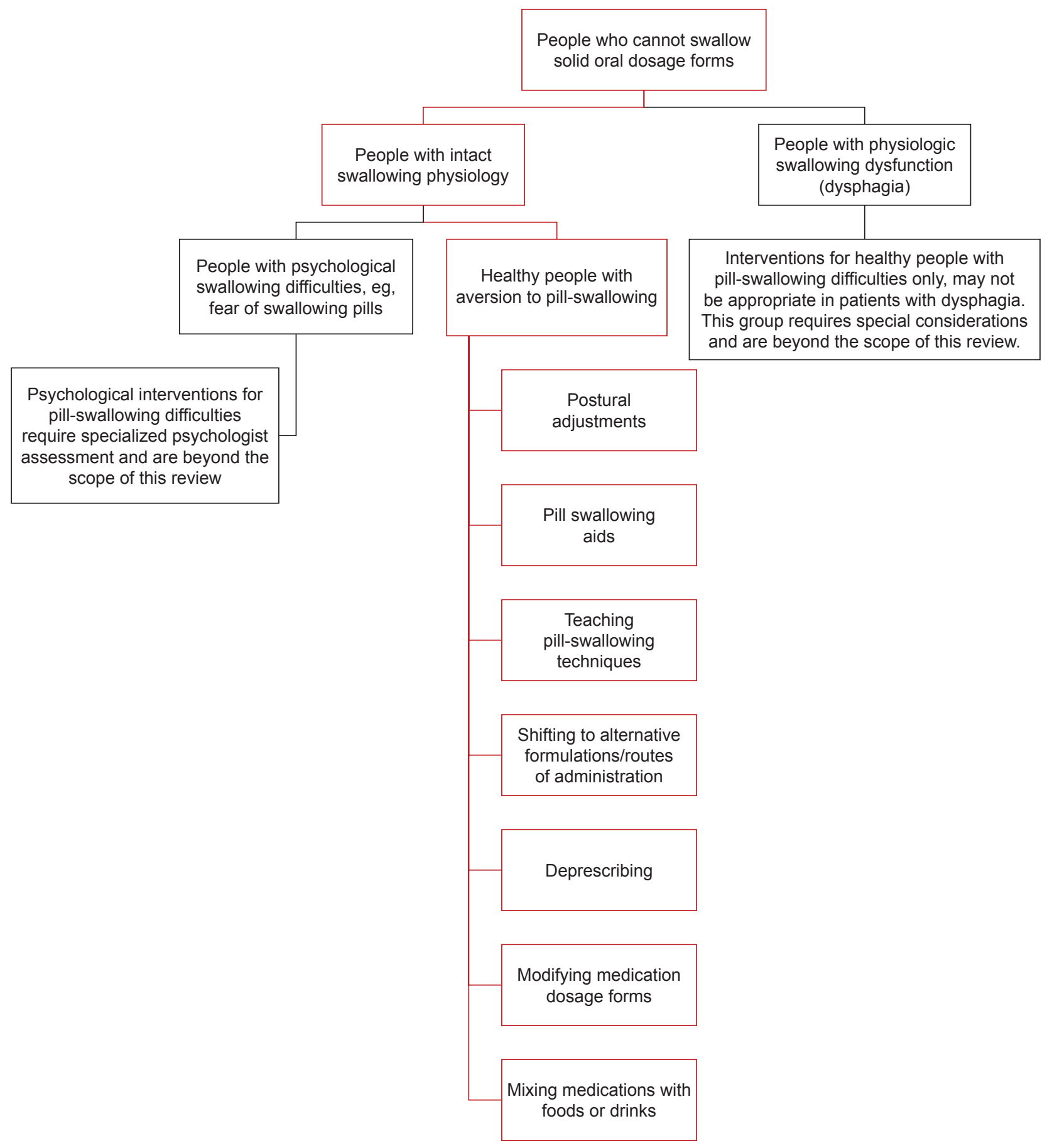

Figure I Different directions of medication management in people with pill-swallowing difficulties.

enter the esophagus and minimizes the chance of aspiration of the oral content into the lungs.

Two studies have investigated postural adjustments in pill swallowing among healthy adults with and without difficulty swallowing pills and using subjective reports from the participants. ${ }^{17,18}$ One study investigated adjusting to central, chin up, chin down, as well as lateral rotation to right and left side. The central head position was favored the most by healthy volunteers with no pill-swallowing difficulties, followed by the lateral head positions. ${ }^{18}$ Those participants with pill-swallowing difficulties endorsed the central (33\% of participants) and chin down (33\% of participants) as the most favorable positions. ${ }^{18}$ The other study considered two different swallowing techniques for tablets and capsules of varying sizes and shapes. ${ }^{17}$ The "lean-forward" technique for swallowing capsules involves taking a medium sized sip of water while the capsule is placed on the tongue, followed by bending the head forward and swallowing the capsule and 
Table I Postural adjustments for regulating the direction and flow of ingested materials to make pills easier to swallow whole

\begin{tabular}{|c|c|c|c|}
\hline Posture & Description & Comments & Illustration \\
\hline Pop-bottle & $\begin{array}{l}\text { - Place a tablet on the tongue, } \\
\text { and swallow it with water from a } \\
\text { flexible container through a suction } \\
\text { motion while tilting the head back } \\
\text { - Helps movement of the bolus from } \\
\text { the front of the mouth to the back }\end{array}$ & $\begin{array}{l}\text { - Nearly } 60 \% \text { of healthy participants, with } 55 \% \text { of them } \\
\text { self-reporting difficulty swallowing pills, reported } \\
\text { improved medication swallowing ability }{ }^{17} \\
\text { - Not considered safe in patients with dysphagia due to } \\
\text { risk of aspiration as it encourages head back posture } \\
\text { that opens the entrance to the airways } \\
\text { - The most preferred position by children (36\%) with pill- } \\
\text { swallowing difficulties }{ }^{18}\end{array}$ & \\
\hline $\begin{array}{l}\text { Lean-forward } \\
\text { (chin down or } \\
\text { chin tuck) }\end{array}$ & $\begin{array}{l}\text { - Place a capsule on the tongue and } \\
\text { take a sip of water, bend the head } \\
\text { forward and tuck the chin toward } \\
\text { the chest, and then swallow the } \\
\text { capsule with the water } \\
\text { - Enhances the protective function } \\
\text { of epiglottis. Widens the valleculae, } \\
\text { narrows the airway, and allows } \\
\text { the epiglottis to be further pushed } \\
\text { toward the back of the throat }\end{array}$ & $\begin{array}{l}\text { - Improved swallowing ability in } 90 \% \text { of participants } \\
\text { in a mixed sample of people with and without pill- } \\
\text { swallowing difficulties in one study } 17 \\
\text { - In another study, } 33 \% \text { of the participants with pill- } \\
\text { swallowing difficulties endorsed this position }{ }^{18} \\
\text { - Although it has shown to prevent aspiration in } \\
32 \%-55 \% \text { of patients with dysphagia, the risk still exists } \\
\text { when this technique is used in these patients }{ }^{16,19,20} \\
\text { - No evidence available around the effectiveness of this } \\
\text { technique in pill-swallowing in patients with dysphagia }\end{array}$ & \\
\hline $\begin{array}{l}\text { Central head } \\
\text { posture }\end{array}$ & $\begin{array}{l}\text { - Keep the head straight with no } \\
\text { rotation or bending }\end{array}$ & $\begin{array}{l}\text { - Improved swallowing ability in } 33 \% \text { of otherwise healthy } \\
\text { people with pill-swallowing difficulties only }{ }^{18} \\
\text { - No evidence available about the safety and efficacy in } \\
\text { medication swallowing difficulty due to dysphagia }\end{array}$ & \\
\hline
\end{tabular}

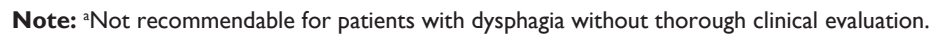

water together (Table 1). The "pop-bottle" technique for swallowing tablets involves placing a tablet on the tongue and closing the lips tightly around a flexible container such as a plastic bottle. The consumer then swallows the tablet through a suction motion of water as they tilt the head back (Table 1). These two techniques showed notable improvement in medication swallowing in a mixed sample of healthy people with and without pill-swallowing difficulties. ${ }^{17}$ Overall, the lean-forward technique for capsules showed higher effectiveness by improving the swallowing ability in $88.6 \%(31 / 35)$ of participants, compared to the pop-bottle method for swallowing tablets with improved swallowing in $59.7 \%(169 / 283)$ of participants. Moreover, the lean forward technique was more successful in improving the ability to swallow large and very large pills compared to the pop-bottle technique. Since the examinations were conducted in two groups of varying sample size, it was not possible to compare the effectiveness statistically.

It is worth noting that safety and usefulness of postural adjustments for medication swallowing difficulties are different between patients who have clinical dysphagia and those who solely have problems swallowing pills without dysphagia. For the former, some postural adjustments such as the pop-bottle technique would not be considered safe as it will increase the risk of choking and aspiration of both the liquid and the medication. ${ }^{17}$ Even the lean forward position is not suitable for all individuals with dysphagia due to the risk of aspiration. ${ }^{16,19,20}$ Postural adjustments when combined with other physiological issues associated with swallowing, such as impaired hyolaryngeal elevation, pharyngeal delay, or impaired cricopharyngeal function, can actually have a counter effect in these patients. Therefore, postural adjustments for patients with clinical dysphagia must be determined by physicians and/or speech therapists after clinical assessments to avoid risk of aspiration. ${ }^{17}$

\section{Pill-swallowing aids}

Pill-swallowing aids are specifically designed to help people who can otherwise swallow food and liquid, to swallow pills whole, without any need for modification of the dosage form. Pill-swallowing aids come in a variety of forms and structures (Table 2).

Pill-swallowing cups feature a special mouthpiece into which the tablet or capsule is placed. The pill is then carried 
Table 2 Pill-swallowing aids for people with pill-swallowing difficulties ${ }^{\mathrm{a}}$

\begin{tabular}{|c|c|c|c|}
\hline Device & Function & Comments & Illustration \\
\hline $\begin{array}{l}\text { Pill- } \\
\text { swallowing } \\
\text { cups }\end{array}$ & $\begin{array}{l}\text { Pill is placed inside the mouthpiece } \\
\text { so that it enters the mouth and } \\
\text { is swallowed with the flow of the } \\
\text { liquid from the cup }{ }^{21}\end{array}$ & $\begin{array}{l}\text { - No evidence available on effectiveness } \\
\text { and safety in people with or without } \\
\text { pill-swallowing difficulties } \\
\text { - Risk of aspiration in patients with } \\
\text { dysphagia should be considered as it } \\
\text { encourages head back position, use } \\
\text { of thin liquids, and whole pills, any of } \\
\text { which may not be safe for patients with } \\
\text { dysphagia }\end{array}$ & \\
\hline $\begin{array}{l}\text { Pill- } \\
\text { swallowing } \\
\text { straws }\end{array}$ & $\begin{array}{l}\text { Pill is dropped onto the straw shelf } \\
\text { and the straw is placed into the } \\
\text { desired liquid. The consumer then } \\
\text { drinks the liquid from the straw. } \\
\text { The flow of the liquid suspends the } \\
\text { pill and carries it into the mouth } \\
\text { as the pill and liquid are swallowed } \\
\text { together }{ }^{22}\end{array}$ & $\begin{array}{l}\text { - No evidence available on effectiveness } \\
\text { and safety in patients with or without } \\
\text { pill-swallowing difficulties } \\
\text { - The manufacturers state that the } \\
\text { straws reduce or eliminate gagging and } \\
\text { choking but no evidence is available. }{ }^{22} \\
\text { Pill swallowing through the straw } \\
\text { encourages the head neutral (central) or } \\
\text { chin-down position, which are favored } \\
\text { by people with pill-swallowing difficulties } \\
\text { - Risk of aspiration in patients with } \\
\text { dysphagia should be considered as it } \\
\text { requires the use of thin liquids and } \\
\text { whole pills, both of which may not be } \\
\text { safe for patients with dysphagia }{ }^{23-25}\end{array}$ & \\
\hline $\begin{array}{l}\text { Pill coating } \\
\text { devices }\end{array}$ & $\begin{array}{l}\text { Pill is pushed through the } \\
\text { applicator, which covers it with } \\
\text { the flavored, slippery coating. This } \\
\text { makes tablet easier to swallow and } \\
\text { masks the taste }\end{array}$ & $\begin{array}{l}\text { - Improved pill swallowing in } 40 / 4 \text { I of } \\
\text { healthy adults with pill-swallowing } \\
\text { difficulties with } 54 \% \text { reporting that } \\
\text { swallowing pills become "much easier" }{ }^{27} \\
\text { - Improved flavor reported by } 100 \% \text { of } \\
\text { participants }{ }^{27} \\
\text { - Generally regarded as safe in terms of } \\
\text { interacting with drugs }{ }^{27} \\
\text { - No evidence is available in patients with } \\
\text { dysphagia }\end{array}$ & \\
\hline $\begin{array}{l}\text { Lubricant } \\
\text { gels }\end{array}$ & $\begin{array}{l}\text { - Pills are placed on a tablespoon } \\
\text { and covered with a spoonful of gel } \\
\text { before administering to patients } \\
\text { - Lubricates and hides the solid dosage } \\
\text { forms within the gel, and therefore } \\
\text { makes them easier to swallow and } \\
\text { slip down the oropharyngeal tract. } \\
\text { - The flavored formulation can mask } \\
\text { unpleasant tastes }\end{array}$ & $\begin{array}{l}\text { - No evidence currently available for } \\
\text { effectiveness and safety in people with } \\
\text { or without pill-swallowing difficulties } \\
\text { - No physicochemical interactions with } \\
\text { medications tested }{ }^{26} \\
\text { - No evidence in patients with dysphagia; } \\
\text { consider whether the thickness of the } \\
\text { gel is appropriate to prevent aspiration }\end{array}$ & \\
\hline $\begin{array}{l}\text { Lubricant } \\
\text { sprays }\end{array}$ & $\begin{array}{l}\text { - Several puffs sprayed to the back of } \\
\text { the mouth and throat before taking } \\
\text { pills } \\
\text { - Lubricates the oral cavity and } \\
\text { masks unpleasant tastes }\end{array}$ & $\begin{array}{l}\text { - Improved pill swallowing among } \\
\text { adolescents with self-reported pill- } \\
\text { swallowing difficulties }{ }^{28} \\
\text { - No evidence available in patients with } \\
\text { dysphagia }\end{array}$ & \\
\hline
\end{tabular}

Note: ${ }^{N}$ Not recommendable for patients with dysphagia without thorough clinical evaluation. 
into the mouth via the liquid flow and the pill and the liquid mix is concurrently swallowed when the swallow reflex takes over. ${ }^{21}$ Specially designed pill-swallowing straws have a similar mechanism providing a flow of liquid through the straw that suspends and carries the pill with the liquid as it enters the mouth and then is swallowed. ${ }^{22}$ The difference between the two is that while the straws encourage the consumer to maintain central or chin-down head position, the use of cups is usually accompanied by a head back position (Table 2). The manufacturer of the straws states that the straws have the potential to reduce or eliminate gagging and choking, ${ }^{22}$ but no evidence has been published about the safety and efficacy of any of these devices. There are safety concerns regarding the use of pill-swallowing cups and straws in patients with clinical dysphagia, especially those for whom thin liquids are a problem as these aids are designed for use with water or other similar fluid. Their use would increase the risk of the liquid and the dose being delivered to the lungs. ${ }^{23}$ The act of swallowing pills whole, which is the primary aim of these devices, can itself be unsafe for people with dysphagia due to the risk of choking and aspiration. ${ }^{24}$ Moreover, straw drinking can be problematic for people with dysphagia, ${ }^{25}$ and the addition of a solid dosage form can potentially increase the risk of aspiration and choking.

Another approach is to coat the pill with a lubricant coating or gel (Table 2). These gels are designed to cover the pill during swallowing, and lubricate its journey through the esophagus. Published evidence for the effectiveness of these is not yet available, but preliminary studies with a gel that is gaining extensive use in aged care facilities in Australia have shown no physicochemical interactions with the medications tested. ${ }^{26}$ A device that applies a thin coating around the pill, giving a smoother and more slippery feel and masking the taste of medications, has been tested. ${ }^{27}$ Forty out of 41 healthy participants with pill-swallowing difficulties reported improved pill swallowing using these pill coating devices, with $54 \%$ of them finding it "much easier" to swallow whole tablets. ${ }^{27}$ The ingredients used in the medicine coatings are mainly from food sources, and the unpublished pharmacological evaluations have generally regarded them as safe in terms of interacting with medications. ${ }^{27}$

Some pill-swallowing aids are designed to be sprayed in the mouth before taking pills (Table 2). One lubricant and flavored spray has been tested in adolescents with a history of pill-swallowing difficulties, and positive effects on improving the ability of pill swallowing was demonstrated. ${ }^{28}$ In this study, 7 out of 11 participants with past pill-swallowing difficulties were able to swallow tic-tac candies successfully using the pill-swallowing spray. ${ }^{28}$ Further evidence is required around the safety and efficacy of pill coating devices, sprays, or gels in patients with pill-swallowing difficulties, particularly for patients with dysphagia. A thorough swallowing assessment and safety analysis should be performed by qualified health care professionals such as physicians or speech pathologists prior to recommending these products to patients with dysphagia.

\section{Teaching pill-swallowing techniques}

Emotional barriers play an important role in the development of pill-swallowing difficulties. It is important to distinguish people with psychological pill-swallowing difficulties than those without any psychological underlying factors. Moreover, some adults may have never been taught how to swallow pills. ${ }^{2}$ Therefore, it is possible that pill taking behaviors may persist from childhood into adulthood.

Behavioral approaches can help individuals overcome their aversion or fear of swallowing pills and acquire pillswallowing ability. Methods such as positive reinforcement either by rewarding or verbal praise, working on relaxation techniques, learning by imitation or modeling, and learning by repetition and exercise have been successfully implemented to improve pill-swallowing difficulties among children and adolescents. Patients covering an age range of 3-21 years old with particular disorders such as ADHD and HIV/AIDS who had difficulty swallowing pills have shown improvement in their pill-swallowing abilities. ${ }^{29-32}$ Some of the pill-swallowing aids such as pill-swallowing sprays (Table 2) have also been suggested as a viable approach to teach pill-swallowing skills especially to children and adolescents. ${ }^{28}$ The consumers can use the product to learn to swallow pills and cease using the aid once swallowing skills are learnt. The evidence around the usefulness of these methods in adult patients is very limited, but it stands to reason that if such interventions have been effective among children, they have the potential to help adult patients as well. ${ }^{31}$ It should be noted that the interventions for psychological pill-swallowing difficulties - especially in severe instances like the fear of taking pills - require psychologist referral for further assessment. Discussing the psychological interventions for these patients requires specialized psychology expertise, which is beyond the scope of this review and can be the focus of future studies.

\section{Shifting to other formulation/route of administration}

Prescribers can substitute solid dosage forms with commercially available liquid formulations if a patient with medication swallowing difficulties is able to swallow liquids while having difficulties with swallowing solids. ${ }^{3}$ If the swallowing problem solely relates to the size of the pills, the prescriber may consider changing to a smaller size of the same pill if 
available. Dispersible or orally disintegrating tablet/granules and lyophilized wafers, which are designed to dissolve in the presence of saliva, water or other liquids, can also be considered for these patients. ${ }^{3,33,34} \mathrm{Few}$ medicines have these options commercially available, and so in the absence of an alternative oral formulation for a specific drug, extemporaneous compounding services are offered by many community pharmacies, with some offering specialized compounding services. A medicine can be converted into a variety of dosage forms, such as a liquid, orally dissolving tablets, troches (lozenges), or even lollipops. Hospital pharmacies can also provide certain extemporaneously prepared formulations in the hospital settings. ${ }^{13}$ Extemporaneous compounds are offered in a range of forms from topical formulations, oral liquids, suppositories, and pessaries to more complex compounds such as parenteral and ophthalmic formulations that require specialized training and facilities. ${ }^{35}$

Health care professionals may also resort to using other routes of administration for patients with pill-swallowing difficulties. Alternative routes such as buccal, rectal, subcutaneous, intramuscular and intravenous injections, or transdermal patches can be considered in case that the oral route is not favored by the patient, is not preferred, or should be avoided (eg, patients with severe dysphagia). ${ }^{10}$ Nevertheless, the lack of alternative formulations/routes of administration for some medicines, combined with higher cost of alternatives, or lack of awareness of health care professionals about the existing alternatives can limit the application of these strategies. Many commonly used medications in adults such as hypoglycemic agents, anti-hypertensives, or anti-dyslipidemia drugs are only available in solid oral dosage forms without offering alternatives for patients with special swallowing needs. Moreover, some of these alternative routes of administration are deemed invasive and require specially trained professionals to perform the administration. Therefore, they are unlikely to be recommended for long-term use. The selection of alternative methods requires precise evaluation of options coupled with assessment of swallowing adequacy to make the best personalized decision. Health care professionals should be cautious when making these adjustments as the alternative formulations and routes of administration may possess different pharmacokinetic profiles or present erratic absorption rates that can affect therapeutic outcomes. ${ }^{36}$

\section{Deprescribing}

Pharmacists or physicians can review patient medication lists to identify any medications that are not vital or necessary and can safely be stopped. ${ }^{37,38}$ If the pill-swallowing problem is expected to be short-term, the prescriber may decide to temporarily discontinue some of the long-term medicines instead of imposing the risks of swallowing medicines, such as choking. ${ }^{3}$ Medication review services offered by pharmacists are of paramount importance in this regard. These reviews can help clinicians identify the medications that are no longer indicated for the patient, and those that are particularly problematic. The prescriber can then consider discontinuing or using alternatives for that particular drug. Another benefit of medication reviews would be to identify patients with or at risk of swallowing difficulties due to the use of medications with the potential of causing swallowing difficulties as their side effect. ${ }^{39}$

\section{Modifying medication dosage forms}

When no other strategies are successful in resolving pillswallowing difficulties, modifying solid dosage forms could be considered to aid swallowing if modification is not specifically contraindicated. Solid dosage forms are usually modified by methods like crushing, cutting, or splitting tablets or opening capsules and sometimes crushing the pellets inside of capsules. For this purpose, patients and health care professionals use a variety of devices. These include appliances as simple as a spoon or knife, syringes, or special equipment such as a mortar and pestle, or a manual or automatic pill crushing device. Dosage form modification should generally be kept as the last resort as it can expose patients to clinically significant adverse drug events (Table 3). For

Table 3 Implications of dosage form modification

\begin{tabular}{|c|c|}
\hline Instance of modification & Implication \\
\hline $\begin{array}{l}\text { - Controlled release } \\
\text { and sustained release } \\
\text { formulations }\end{array}$ & $\begin{array}{l}\text { - Erratic/delayed absorption } \\
\text { - Toxic/sub-therapeutic doses } \\
\text { - Increased risk of side effects }\end{array}$ \\
\hline $\begin{array}{l}\text { Enteric-coated } \\
\text { formulations }\end{array}$ & $\begin{array}{l}\text { - Altered absorption } \\
\text { - Increased side effects such as gastric } \\
\text { irritation } \\
\text { - Instability and inactivity of medication }\end{array}$ \\
\hline $\begin{array}{l}\text { - Sugar-coated formulations } \\
\text { - Film-coated formulations } \\
\text { - Light-sensitive } \\
\text { formulations } \\
\text { - Humidity-sensitive } \\
\text { formulations }\end{array}$ & $\begin{array}{l}\text { - Altered taste } \\
\text { - Decreased adherence } \\
\text { - Physicochemical instability }\end{array}$ \\
\hline $\begin{array}{l}\text { - Hormonal or cytotoxic } \\
\text { medications }\end{array}$ & $\begin{array}{l}\text { - Occupational exposure of health } \\
\text { care professionals } \\
\text { - Inhalation of drug particles } \\
\text { - Dermal contact } \\
\text { - Risk of allergies, infertility, congenital } \\
\text { malformations, abortion }\end{array}$ \\
\hline $\begin{array}{l}\text { - Process of dosage form } \\
\text { modification }\end{array}$ & $\begin{array}{l}\text { - Powder loss/spillage } \\
\text { - Inaccurate dosing } \\
\text { - Cross-contamination } \\
\text { - Physicochemical incompatibility of } \\
\text { mixed medications }\end{array}$ \\
\hline
\end{tabular}


instance, modifying sustained/controlled release formulations can change the rate and the extent of absorption, which can consequently lead to drug toxicity and even death. ${ }^{15}$ Physicochemical properties of medications can also change in the process of modification. The protective coating of some pills gets destroyed during the modification process, inactivating the ingredients or increasing their side effects. ${ }^{40}$ Unpalatability is another problem with altered dosage forms as the taste or texture of the modified drug may become unpleasant. ${ }^{37}$

The process of dosage form modification itself can contribute to some problems. Powder spillage/loss or powder residues in crushing equipment like mortar and pestle ${ }^{41-43}$ can result in reduced therapeutic efficacy due to incomplete or inconsistent drug delivery. This is particularly concerning for drugs with a narrow therapeutic index, ${ }^{13,41}$ or drugs with concentration-dependent pharmacodynamics. Another risk of the modification process is cross-contamination of medications when the same crushing equipment is used for multiple patients without proper cleaning between patients. ${ }^{44}$

Aside from the impact on patients, health care professionals may be exposed to the occupational hazards associated with dosage form modification practices through direct contact or inhalation of the particles released during the modification process. ${ }^{45}$ This is of particular concern with special medications such as cytotoxic and hormonal medications. ${ }^{42}$

\section{Mixing medications in foods or drinks}

Foods or drinks such as yoghurt, jam, juices, and milk are used as an aid in which the whole pills can be hidden or crushed tablets or capsule contents are mixed to facilitate swallowing and improve the palatability of the medication particles. ${ }^{14,33}$ Mixing medicines with foods or drinks increases the possibility of food-drug interactions and can potentially result in increased or decreased therapeutic effect by altering the bioavailability of the drug. ${ }^{46,47}$ Food-drug interactions and their possible consequences are well reported in the literature. ${ }^{48}$ For instance, dairy products containing calcium can chelate certain medications and alter absorption of the drug, ${ }^{46}$ or acidic beverages may change the absorption profile and bioavailability of medications due to $\mathrm{pH}$ changes. ${ }^{46}$ Another concern associated with mixing drugs with foods or drinks is unfinished food portions, which can lead to incomplete medication dosing. ${ }^{14}$ Special attention should be paid to the consistency and type of foods in which the medications are mixed in patients with dysphagia, as these patients may only be able to take foods of certain consistencies. Although it is more common for crushed medications to be added to food or liquids, some people use food to assist them with swallowing solid dose medications whole. For example, the solid dose is wrapped in a small piece of bread or inserted into a grape or piece of banana, allowing the person to slightly chew the food and trigger a normal swallow reflex allowing them to swallow the partially chewed food item and the medication hidden within it. There is very limited published literature on this phenomenon; ${ }^{28}$ however, patients have described the process clinically, and there are websites that recommend people practice learning to swallow solid doses by rolling up pieces of bread and swallowing bread balls that are gradually increased in size. ${ }^{49}$ The theory is that we are used to swallowing food pieces that are larger than solid doses and that food can be used as a bridge to help healthy people learn to swallow tablets and capsules. This method should not be used for people with dysphagia as it may result in choking.

\section{Conclusion}

For many people, the mere act of swallowing pills is troublesome due to various psychological and physiological factors. Overall, the problem of medicine administration to people with pill-swallowing difficulties is a multifaceted issue. While understanding and resolving the underlying causes of medication swallowing problems is generally the preferred approach, sometimes this may not be possible. Design of alternative medication formulations suitable to meet the needs of people with pill-swallowing difficulties can be a promising direction for the future. Prescribing, supplying, and administering medications to people with pill-swallowing difficulties should also be managed by wiser and better utilization of what is currently available to assist these people. As highlighted in this review, there are possible ways to achieve this goal. Healthy individuals with pill-swallowing difficulties can potentially benefit from several strategies and techniques designed to facilitate swallowing medications. Nevertheless, these methods should be validated using objective assessment such as video fluoroscopic swallowing study, which is the gold standard for assessing swallowing performance for their safety and effectiveness before being used in practice. It should be noted that this review has focused on strategies for otherwise healthy people with pill-swallowing difficulties only, while the considerations for people with clinical dysphagia are more complicated and need to be discussed separately in future studies.

\section{Disclosure}

The authors report no conflicts of interest in this work. 


\section{References}

1. Liu F, Ghaffur A, Bains J, Hamdy S. Acceptability of oral solid medicines in older adults with and without dysphagia: a nested pilot validation questionnaire based observational study. Int J Pharm. 2016;512(2): 374-381.

2. Lau ETL, Steadman KJ, Mak M, Cichero JAY, Nissen LM. Prevalence of swallowing difficulties and medication modification in customers of community pharmacists. J Pharm Pract Res. 2015;45(1):18-23.

3. Kelly J, Wright D. Administering medication to adult patients with dysphagia. Nurs Stand. 2009;23(29):62-68.

4. Tahaineh L, Wazaify M. Difficulties in swallowing oral medications in Jordan. Int J Clin Pharm. 2017;39(2):373-379.

5. PR Newswire. $40 \%$ of American adults report experiencing difficulty swallowing pills - national survey shows many failed to take medication as directed - because of difficulty swallowing pills. New York: PR Newswire Association LLC; 2004. https://jacksonbondenterprises. wordpress.com/2013/09/18/40-of-american-adults-report-experiencingdifficulty-swallowing-pills/. Accessed July 11, 2017.

6. Schiele JT, Quinzler R, Klimm HD, Pruszydlo MG, Haefeli WE. Difficulties swallowing solid oral dosage forms in a general practice population: prevalence, causes, and relationship to dosage forms. Eur $J$ Clin Pharmacol. 2013;69(4):937-948.

7. Duggan JM, Shukla V, Akpanudo B, Gutterson G, Eitniear L, Sahloff E. Doc, I just can't swallow pills: HIV infected patients and pill phagophobia. J AIDS Clin Res. 2014;5(9):348.

8. Marquis J, Schneider MP, Payot V, et al. Swallowing difficulties with oral drugs among polypharmacy patients attending community pharmacies. Int J Clin Pharm. 2013;35(6):1130-1136.

9. Strachan I, Greener M. Medication-related swallowing difficulties may be more common than we realise. Pharm Pract. 2005;15(10):411-414.

10. Wright D. Medication administration in nursing homes. Nurs Stand. 2002;16(42):33-38.

11. Fusco S, Cariati D, Schepisi R, et al. Management of oral drug therapy in elderly patients with dysphagia. J Gerontol Geriatr. 2016;64(1): 9-20.

12. Forough AS, Wong SYM, Lau ETL, et al. Nurse experiences of medication administration to people with swallowing difficulties living in aged care facilities: a systematic review of qualitative evidence. $J B I$ Database System Rev Implement Rep. 2018;16(1):71-86.

13. Nissen LM, Haywood A, Steadman KJ. Solid medication dosage form modification at the bedside and in the pharmacy of Queensland hospitals. $J$ Pharm Pract Res. 2009;39(2):129-134.

14. Mercovich N, Kyle GJ, Naunton M. Safe to crush? A pilot study into solid dosage form modification in aged care. Australas $J$ Ageing. 2014;33(3):180-184.

15. Schier JG, Howland MA, Hoffman RS, Nelson LS. Fatality from administration of labetalol and crushed extended-release nifedipine Ann Pharmacother. 2003;37(10):1420-1423.

16. Terré R, Mearin F. Effectiveness of chin-down posture to prevent tracheal aspiration in dysphagia secondary to acquired brain injury. A videofluoroscopy study. Neurogastroenterol Motil. 2012;24(5):414-419.

17. Schiele JT, Schneider H, Quinzler R, Reich G, Haefeli WE. Two techniques to make swallowing pills easier. Ann Fam Med. 2014;12(6): $550-552$.

18. Kaplan BJ, Steiger RA, Pope J, Marsh A, Sharp M, Crawford SG. Successful treatment of pill-swallowing difficulties with head posture practice. Paediatr Child Health. 2010;15(5):e1-e5.

19. Logemann JA, Gensler G, Robbins J, et al. A randomized study of three interventions for aspiration of thin liquids in patients with dementia or Parkinson's disease. J Speech Lang Hear Res. 2008;51(1):173-183.

20. Bülow M, Olsson R, Ekberg O. Videomanometric analysis of supraglottic swallow, effortful swallow, and chin tuck in patients with pharyngeal dysfunction. Dysphagia. 2001;16(3):190-195.

21. Yetzer E, Blake K, Goetsch N, Shook M, St Paul M. SAFE medication management for patients with physical impairments of stroke, part one. Rehabil Nurs. 2015;40(4):260-266.
22. MediStraw [homepage on the Internet]. Pill taking made E-Z 2006 [cited December 2, 2016]. Available from: http://www.medistraw.com/. Accessed March 29, 2017.

23. Schiele JT, Penner H, Schneider H, et al. Swallowing tablets and capsules increases the risk of penetration and aspiration in patients with stroke-induced dysphagia. Dysphagia. 2015;30(5):571-582.

24. Carnaby-Mann G, Crary M. Pill swallowing by adults with dysphagia. Arch Otolaryngol Head Neck Surg. 2005;131(11):970-975.

25. González-Fernández M, Daniels SK. Dysphagia in stroke and neurologic disease. Phys Med Rehabil Clin N Am. 2008;19(4):867-888, x.

26. Crino L, Manrique-Torres YJ, Cichero JA, Steadman KJ. Characterization of Gloup: is it suitable for medication delivery in dysphagic patients? APSA-ASCEPT Joint Scientific Meeting; November 29-December 2, 2015; Hobart, Tasmania.

27. Uloza V, Uloziene I, Gradauskiene E. A randomized cross-over study to evaluate the swallow-enhancing and taste-masking properties of a novel coating for oral tablets. Pharm World Sci. 2010;32(4):420-423.

28. Diamond S, Lavallee DC. Experience with a pill-swallowing enhancement aid. Clin Pediatr (Phila). 2010;49(4):391-393.

29. Czyzewski DI, Calles NR, Runyan RD, Lopez MA. Teaching and maintaining pill swallowing in HIV-infected children. AIDS Read. 2000;10(2):88-95.

30. Beck MH, Cataldo M, Slifer KJ, Pulbrook V, Guhman JK. Teaching children with attention deficit hyperactivity disorder (ADHD) and autistic disorder (AD) how to swallow pills. Clin Pediatr (Phila). 2005;44(6):515-526.

31. Garvie PA, Lensing S, Rai SN. Efficacy of a pill-swallowing training intervention to improve antiretroviral medication adherence in pediatric patients with HIV/AIDS. Pediatrics. 2007;119(4):e893-e899.

32. Hansen DL, Tulinius D, Hansen EH. Adolescents' struggles with swallowing tablets: barriers, strategies and learning. Pharm World Sci. 2008;30(1):65-69.

33. Haw C, Stubbs J. Administration of medicines in food and drink: a study of older inpatients with severe mental illness. Int Psychogeriatr. 2010;22(3):409-416.

34. Kaur T, Gill B, Kumar S, Gupta GD. Mouth dissolving tablets: a novel approach to drug delivery. Int J Curr Pharm Res. 2011;3(1):1-7.

35. Falconer JR, Steadman KJ. Extemporaneously compounded medicines. Aust Prescr. 2017;40(1):5.

36. Lugo RA, Kern SE. The pharmacokinetics of oxycodone. J Pain Palliat Care Pharmacother. 2005;18(4):17-30.

37. Kelly J, D'Cruz G, Wright D. A qualitative study of the problems surrounding medicine administration to patients with dysphagia. Dysphagia. 2009;24(1):49-56.

38. Wright D. Swallowing difficulties protocol: medication administration. Nurs Stand. 2002;17(14-15):43-45.

39. McLachlan AJ, Ramzan I. Misuse of formulations in the aged care setting. In: Koch S, Gloth FM, Nay R, editors. Medication Management in Older Adults: A Concise Guide for Clinicians. London: Springer; 2010:95-104

40. Burridge N, Deidun D. Australian Don't Rush to Crush Handbook: Therapeutic Options for People Unable to Swallow Solid Oral Medicines. 1st ed. Collingwood, VIC: Society of Hospital Pharmacists of Australia; 2011

41. Paradiso LM, Roughead EE, Gilbert AL, et al. Crushing or altering medications: what's happening in residential aged-care facilities? Australas J Ageing. 2002;21(3):123-127.

42. Stubbs J, Haw C, Dickens G. Dose form modification - a common but potentially hazardous practice. A literature review and study of medication administration to older psychiatric inpatients. Int Psychogeriatr. 2008;20(3):616-627.

43. Thong MY, Manrique YJ, Steadman KJ. Drug loss while crushing tablets: comparison of 24 tablet crushing devices. PLoS One. 2018; 13(3): 0193683

44. Mc Gillicuddy A, Crean AM, Sahm LJ. Older adults with difficulty swallowing oral medicines: a systematic review of the literature. Eur J Clin Pharmacol. 2016;72(2):141-151. 
45. Valanis B, Vollmer WM, Steele P. Occupational exposure to antineoplastic agents: self-reported miscarriages and stillbirths among nurses and pharmacists. J Occup Environ Med. 1999;41(8):632-638.

46. Schmidt LE, Dalhoff K. Food-drug interactions. Drugs. 2002;62(10): 1481-1502.

47. Manrique YJ, Lee DJ, Islam F, et al. Crushed tablets: does the administration of food vehicles and thickened fluids to aid medication swallowing alter drug release? J Pharm Pharm Sci. 2014;17(2): 207-219.
48. McCabe-Sellers B, Frankel EH, Wolfe JJ. Handbook of Food-Drug Interactions. Boca Raton, FL: CRC Press; 2003.

49. Shrager L [webpage on the Internet]. It can be a hard pill to swallow 2011 [cited January 15, 2018]. Available from: https://www.everydayhealth.com/columns/lynda-shrager-the-organized-caregiver/it-can-bea-hard-pill-to-swallow/. Accessed January 20, 2018.

\section{Publish your work in this journal}

Patient Preference and Adherence is an international, peer-reviewed, open access journal that focuses on the growing importance of patient preference and adherence throughout the therapeutic continuum. Patient satisfaction, acceptability, quality of life, compliance, persistence and their role in developing new therapeutic modalities and compounds to optimize clinical outcomes for existing disease states are major areas of interest for the journal. This journal has been accepted for indexing on PubMed Central. The manuscript management system is completely online and includes a very quick and fair peer-review system, which is all easy to use. Visit http://www dovepress.com/testimonials.php to read real quotes from published authors.

Submit your manuscript here: http://www.dovepress.com/patient-preference-and-adherence-journal 